\title{
Probleemgestuurd leren: een literatuuroverzicht
}

\author{
J. Beullens, $\mathrm{H}$. Jaspaert
}

\section{Samenvatting}

Inleiding: In dit artikel wordt een overzicht geboden van de stand van zaken betreffende probleemgestuurd leren, waarbij onderscheid gemaakt wordt tussen een probleemgestuurd curriculum en probleemgestuurd leren als component in een traditioneel curriculum.

Methode: Er is een Medline-search gedaan voor de periode 1966 tot 1999 betreffende probleemgestuurd onderwijs in geneeskundeopleidingen.

Resultaten: Over het algemeen oordelen studenten in een probleemgestuurd curriculum gunstiger over het onderwijs dan hun collega's die een traditioneel curriculum volgen. Studenten uit een probleemgestuurd curriculum zoeken meer materiaal zelf op en hebben doorgaans een grondiger leerstijl. Wat betreft kennis en kunde zijn de verschillen op het gebied van de basisvakken in het voordeel van het traditionele curriculum en op het gebied van de klinische competentie in het voordeel van het probleemgestuurde curriculum. Studenten uit een traditionele onderwijsinstelling die deelnemen aan een probleemgestuurde onderwijscomponent hebben daarover een positief oordeel. Bovendien presteren ze even goed of beter dan hun collega's die uitsluitend traditioneel onderwijs volgen.

Discussie: Hoewel bij veel van de onderzoeken kritische kanttekeningen te plaatsen zijn, is duidelijk dat studenten probleemgestuurd onderwijs waarderen. Traditioneel onderwijs leidt veelal tot betere scores op de basisvakken en probleemgestuurd onderwijs op betere scores voor gedragswetenschappen en klinische competentie. Het lijkt erop dat de kennisverwerving in het traditionele onderwijs verbeterd kan worden door probleemgestuurde componenten in te lassen. Meer experimenteel onderzoek is nodig naar onderdelen van probleemgestuurde onderwijsbenaderingen die het leren van studenten gunstig beïnvloeden. (Beullens J, Jaspaert $H$. Probleemgestuurd leren: een literatuuroverzicht. Tijdschrift voor Medisch Onderwijs 2001;20(3): 100-113.)

\section{Inleiding}

In 1993 verschenen in Academic Medicine twee artikelen die een overzicht geven van onderzoek naar de effecten van probleemgestuurd leren in de periode van 19701992.12 Recent werd een derde overzichtsartikel gepubliceerd, dat de periode van 1992 tot 1998 omvat. $^{3}$

Probleemgestuurd medisch onderwijs wordt gedefinieerd als onderwijs dat gekenmerkt wordt door (a) de bestudering van klinische gevallen, reëel of hypothetisch, (b) kleine discussiegroepen, (c) zelfstudie, (d) hypothetisch-deductief redeneren, en (e) een centrale plaats voor het leren van de student. ${ }^{2}$ Het probleemgestuurd onderwijs wordt onderbouwd door de theorie van de informatieverwerking en verschillende concepten uit de cognitieve psychologie, zoals contextueel leren, coöperatief leren, actieve betrokkenheid bij het leren en zelfregulerend leren. ${ }^{4}$ Op het eerste gezicht lijkt probleemgestuurd onderwijs de integratie en verwerking van kennis in een klinische context te bevorderen, waardoor de toepassing van kennis in de praktijk vergemakkelijkt wordt. 
Er is veel onderzoek gedaan naar de effecten van probleemgestuurd leren. In tegenstelling tot bovenvermelde overzichten wordt in het onderstaande overzicht van vergelijkingen tussen probleemgestuurd en traditioneel onderwijs onderscheid gemaakt tussen probleemgestuurde curricula en probleemgestuurde onderwijscomponenten in een traditioneel curriculum.

\section{Methode}

Er werd een Medline-search gedaan over de periode van 1966 tot 1999 met als trefwoorden 'probleem based learning', 'problem based curriculum', 'problem based education', 'problem oriented learning', 'problem oriented curriculum' en 'problem oriented education'. De literatuurlijsten in de gevonden artikelen leverden weer nieuwe referenties op. Het domein werd beperkt tot de medische opleiding en de daarbij aansluitende vervolgopleidingen.

\section{Leren in een probleemgestuurd curriculum}

\section{Subjectief oordeel van de studenten}

Over het algemeen blijkt dat studenten zeer tevreden zijn over een probleemgestuurd curriculum. ${ }^{6} 7$ Op Dalhousie University werden twee attitudeschalen afgenomen in het traditionele en het probleemgestuurde curriculum. De probleemgestuurde groep heeft een significant gunstiger oordeel. ${ }^{9}$ De psychometrische kwaliteit van de instrumenten wordt echter niet beschreven en het is onduidelijk of de jaarklassen representatief zijn. De enige significante verschillen tussen het probleemgestuurde en traditionele spoor aan de University of New Mexico zijn een positiever oordeel van studenten uit het probleemgestuurde spoor op enkele items van een attitude- schaal. Het oordeel van de studenten uit het traditionele spoor ontwikkelt zich in de loop van één semester in negatieve zin. ${ }^{10}$ In dezelfde universiteit is gedurende vier opeenvolgende semesters een distressschaal afgenomen. Aan het begin van de studie is er geen verschil, maar in het tweede en derde semester is het distressniveau bij de studenten uit het probleemgestuurde spoor significant lager dan bij hun collega's uit het traditionele spoor. ${ }^{11} 12$ Het is echter onduidelijk of de twee groepen studenten representatief zijn.

Afgestudeerden kunnen hun functioneren vergelijken met dat van collega's uit andere faculteiten. Meer dan 90\% van de afgestudeerden van het probleemgestuurde curriculum van McMaster voelt zich op tien van twintig domeinen even goed of beter voorbereid in vergelijking met hun collega's uit andere medische faculteiten. Slechts op twee gebieden ('informatie uit de basiswetenschappen' en 'effecten van geneesmiddelen') voelt meer dan een derde zich slechter voorbereid. ${ }^{13}$ Van de respondenten zou 69\% opnieuw voor een probleemgestuurd curriculum kiezen, 19\% voor een meer traditioneel curriculum met onderwijs in kleine groepen en slechts 3\% voor een echt traditioneel curriculum. ${ }^{14}$

\section{Leeromgeving}

In twee onderzoeken wordt gerapporteerd dat studenten uit een probleemgestuurd curriculum significant meer studiemateriaal zelf selecteren. ${ }^{15} 16$ Opmerkelijk is dat deze verschillen ook gevonden worden in de klinische jaren (3 en 4), terwijl er in die periode weinig verschillen zijn tussen probleemgestuurde en traditionele opleidingen. ${ }^{16}$ Omdat de groepen studenten niet goed vergelijkbaar zijn, kunnen de bevindingen niet alleen verklaard worden door een grotere motivatie tot 
zelfstandig leren bij probleemgestuurde studenten.

De mentale leeromgeving is in twee onderzoeken bestudeerd met behulp van de Medical School Learning Environment Survey (MSLES), een vragenlijst met zeven subschalen: 'flexibiliteit', 'studentstudentinteractie', 'emotioneel klimaat', 'ondersteuning', 'zinvolle leerervaring', 'organisatie' en 'belangstellingsbreedte'. ${ }^{17}$ 18 In drie andere onderzoeken zijn andere vragenlijsten over de leeromgeving afgenomen. ${ }^{12} 1920$ Studenten in een probleemgestuurd curriculum blijken na twee jaar gunstiger te oordelen over hun leeromgeving (behalve wat betreft organisatie en duidelijkheid) dan studenten in een traditioneel curriculum, ongeacht of studenten het probleemgestuurde curriculum volgen uit vrije keus, bij toeval of omdat ze geen keus hadden.12 17-20 De studenten uit het probleemgestuurde spoor scoren echter in het begin van het eerste jaar reeds significant hoger op 'flexibiliteit'. 1718

\section{Leerstijl}

Moore en medewerkers namen in het probleemgestuurde en het traditionele spoor van de Harvard Medical School de Preferred Learning Style Index af in het begin van de opleiding en aan het einde van het tweede jaar. ${ }^{20}$ Reeds bij de start bestaat er in het probleemgestuurde spoor een significante voorkeur voor ontdekkend (studentgestuurd) leren en in het traditionele spoor voor receptief (docentgestuurd) leren. Zelfs na correctie voor deze beginvoorkeur blijven de verschillen in leervoorkeur op het eind van het tweede jaar significant.

Doorgaans wordt er onderscheid gemaakt tussen leerstijlen met een oppervlakkige, een grondige en een strategische aanpak. $^{21}$ In twee onderzoeken met behulp van de 'Lancaster Approaches to
Studying Inventory' is aangetoond dat de aanpak van de studenten uit het probleemgestuurde curriculum op het einde van het eerste jaar significant grondiger en minder oppervlakkig is dan de aanpak van studenten in een traditioneel curriculum. ${ }^{22} 23$ Omdat deze bevindingen verkregen werden met een vragenlijst, hoeven zij niet overeen te komen met het feitelijk studeergedrag.

Onderzoeksbevindingen uit Maastricht suggereren dat onderwijservaringen belangrijk zijn. Op de eerste dag van hun studie en na een introductieperiode van zes weken vulden eerstejaarsstudenten een leerstijlvragenlijst in. Tijdens deze periode vermindert de oppervlakkige aanpak significant, terwijl de grondige en de strategische aanpak significant toenemen. De auteurs schrijven deze veranderingen in leerstijl toe aan de introductie tot probleemgestuurd leren. ${ }^{24}$ Meer onderzoek is vereist om uit te maken of ze daarin gelijk hebben.

\section{Toetsresultaten basisvakken}

Een vergelijking tussen examenresultaten voor de basisvakken in een probleemgestuurd en een traditioneel curriculum is samengevat in tabel 1. De studies uit de Verenigde Staten betreffen studenten uit dezelfde universiteit. Het voordeel hiervan is dat buiten het curriculum de leeromgeving gelijk is. Het nadeel is dat de studenten uit de twee sporen door het uitwisselen van ervaringen elkaar kunnen beïnvloeden. Het feit dat een nationaal examen als toets gebruikt werd, is positief. Bij de samenstelling van de experimentele groep zijn veel methodologische kanttekeningen te plaatsen. De studenten volgen het probleemgestuurde spoor uit vrije keuze of omdat ze daarvoor geselecteerd zijn. In de Nederlandse onderzoeken werden de toetsresultaten op de Maastrichtse voortgangstoets van studen- 


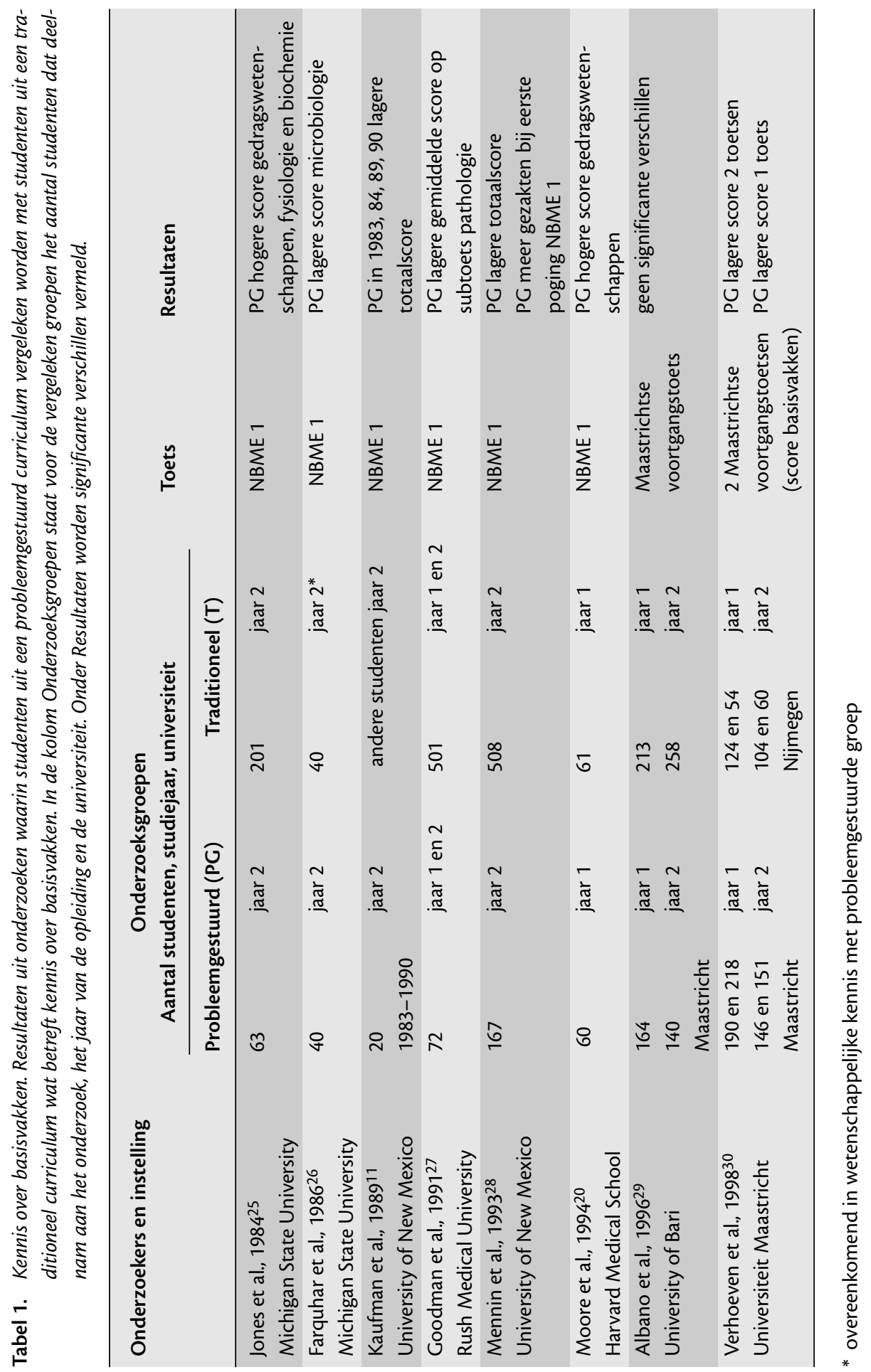


ten uit Maastricht (probleemgestuurd curriculum) vergeleken met die van studenten uit Groningen of Nijmegen (traditioneel curriculum). In Maastricht was deelname aan de toets verplicht, in Nijmegen vrijwillig, wat in het voordeel speelt van de Nijmeegse gemiddelde scores. Alleen de resultaten uit de eerste twee jaren worden beschreven, omdat dit zowel in de Verenigde Staten als in Nederland de jaren zijn waarin de basisvakken centraal staan in het traditionele curriculum. De studenten uit een probleemgestuurd curriculum hebben een significant lagere totaalscore dan hun collega's uit een traditioneel curriculum of er is geen significant verschil. ${ }^{11} 20$ 25-31 Significant meer studenten uit het probleemgestuurde spoor slagen niet in één keer voor het examen van de National Board of Medical Examiners (NBME I) of het percentage geslaagden verschilt niet significant. ${ }^{27} 28$ Zelfs bij gelijke totaalscore zijn er in enkele onderzoeken significante verschillen op subtoetsen in het voordeel van het traditionele curriculum, met name voor microbiologie en pathologie. ${ }^{26} 27$ Over het algemeen behalen de studenten uit het probleemgestuurde curriculum significant hogere scores op de gedragswetenschappen. ${ }^{20} 2930$ In één onderzoek wordt dit ook gevonden voor biochemie en fysiologie. ${ }^{25}$

Aan de University of New Mexico werden studenten at random geplaatst in het probleemgestuurde of het traditionele spoor. Beide groepen hadden een vergelijkbare score op een toelatingsproef (de Medical College Admission Test), wat de toevallige samenstelling bevestigt. Niettemin is in de probleemgestuurde subgroep de score op het NBME I significant lager en het percentage gezakten bij eerste deelname aan dit examen 5,7 maal zo hoog. ${ }^{28}$ Het is voorstelbaar dat de hoge concentratie aan basisvakken in de eerste twee jaren in het traditionele curriculum in het nadeel is van studenten in het probleemgestuurde curriculum, maar dat deze achterstand ingehaald wordt in de volgende jaren van de medische opleiding. In een onderzoek van Verhoeven en medewerkers werd het onderdeel basisvakken uit twee voortgangstoetsen ook geanalyseerd voor de jaren 3 tot $6.30 \mathrm{Bij}$ één toets hebben de derde- en vierdejaarsstudenten uit Nijmegen (traditioneel curriculum) een significant hogere score dan hun collega's uit Maastricht (probleemgestuurd curriculum). In het zesde jaar scoren de Nijmeegse studenten significant hoger op beide toetsen. Bij een vergelijking van derde- tot en met zesdejaars studenten uit vier Europese universiteiten, waaronder Maastricht, worden in de totaalscore wel enkele significante verschillen aangetroffen, maar deze zijn niet systematisch in het voordeel van een bepaald curriculum. De traditionele universiteiten scoren wel significant hoger in de basisvakken. Maastricht scoort significant beter in de gedragswetenschappen. ${ }^{29}$ Er zijn dus wel aanwijzingen dat in een traditioneel curriculum studenten beter voorbereid worden op de basisvakken dan in een probleemgestuurd curriculum, maar de bevindingen zijn niet eenduidig. ${ }^{28}$

\section{Toetsresultaten klinische vakken}

De vergelijkingen betreffende toetsresultaten voor klinische vakken zijn samengevat in tabel 2. Doorgaans betreft het derde- of vierdejaars studenten, omdat tijdens deze jaren in de onderzochte universiteiten in het traditionele curriculum de klinische vakken centraal staan.

Er is geen significant verschil tussen een probleemgestuurd en een traditioneel curriculum in totaalscore op het NBME II. 1127283233 Evenmin is er een significant verschil op het onderdeel klinische vakken uit de voortgangstoets. ${ }^{28} 30$ Ook 


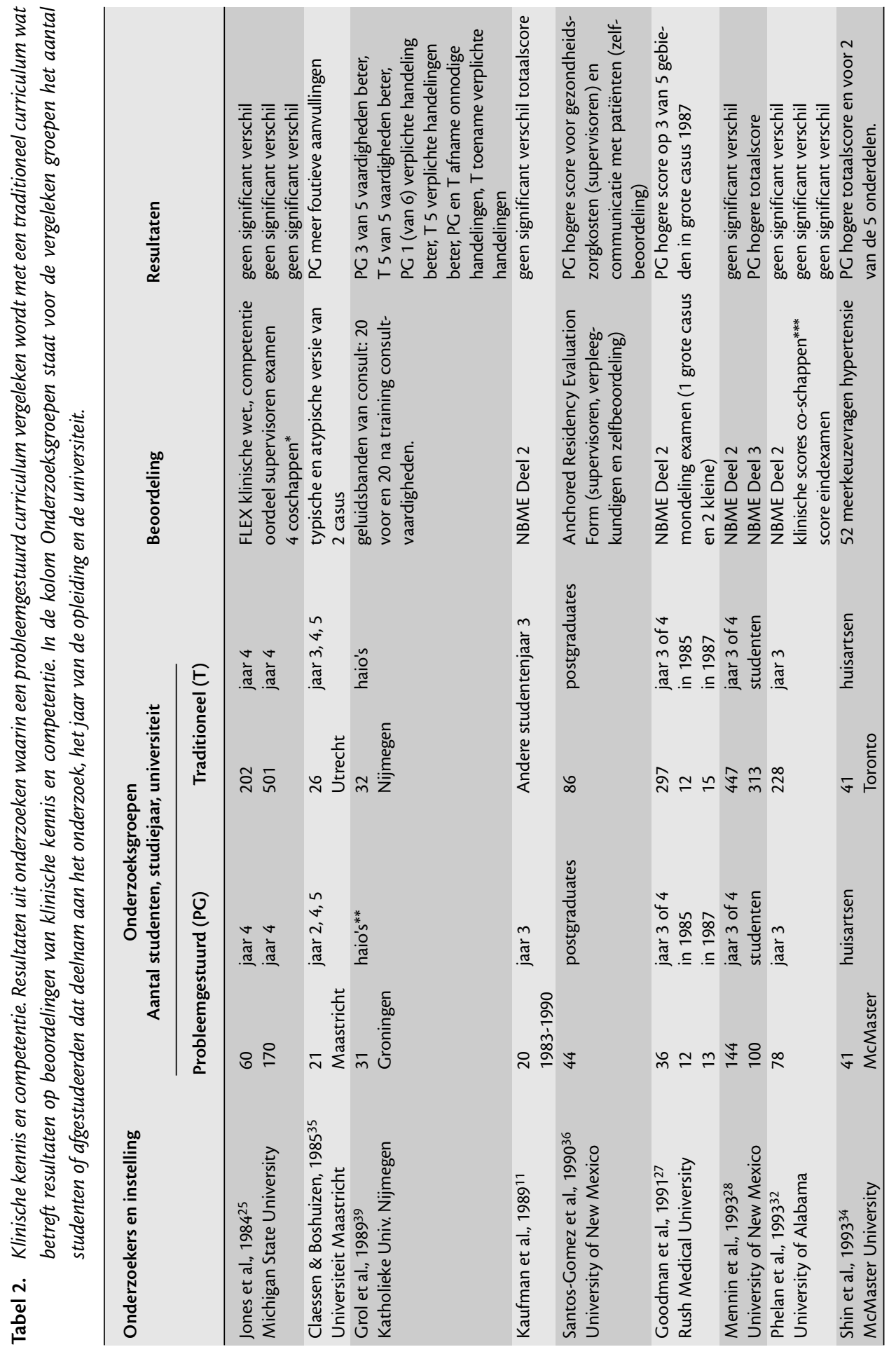




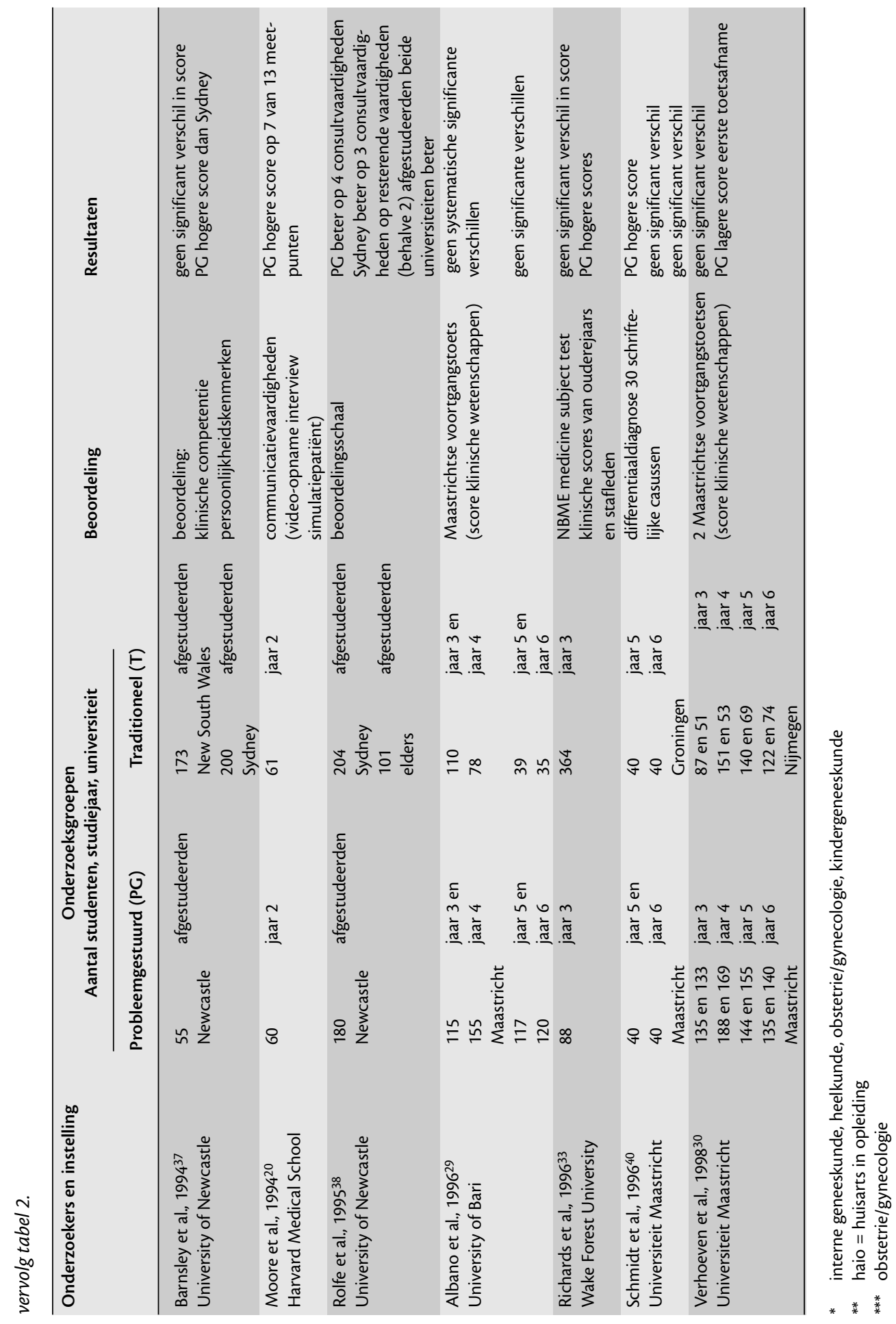


het verschil in resultaten op andere examens is niet significant. ${ }^{11} 2532$ Op een mondeling examen is er geen significant verschil in 1985, terwijl in 1987 de studenten uit het probleemgestuurde spoor een significant hogere score hebben. ${ }^{27}$ Op een toets bestaande uit 52 meerkeuzevragen over het hypertensiebeleid hebben afgestudeerde huisartsen van McMaster (probleemgestuurd curriculum) een significant hogere score dan afgestudeerde huisartsen van de Universiteit van Toronto (traditioneel curriculum). De auteurs geven echter zelf al aan dat dit ook verklaard zou kunnen worden uit een verschil in nadruk op hypertensie tussen beide universiteiten. ${ }^{34} \mathrm{Op}$ het NBME III hebben de studenten uit een probleemgestuurd spoor eveneens een significant hogere score dan hun collega's uit een traditioneel spoor, maar dit examen meet veeleer klinische prestatie dan kennis. ${ }^{28}$ Claessen en Boshuizen gebruikten een experimenteel proefontwerp waarbij een typische en een atypische versie van twee casussen worden aangeboden en studenten onder meer gevraagd wordt alle gegevens over de patiënt die ze zich kunnen herinneren, te noteren. Studenten uit Maastricht (probleemgestuurd curriculum) verschillen niet significant van studenten uit Utrecht (traditioneel curriculum) in reproductiescore, maar produceren significant meer foutieve aanvullingen. ${ }^{32}$ Studenten in het probleemgestuurde spoor van de University of New Mexico verschillen niet significant in scores op NBME II en III van hun collega's in het traditionele spoor. ${ }^{28}$ In het onderzoek waarin Maastricht en Nijmegen vergeleken worden, zijn de resultaten van de klinische vakken ook geanalyseerd voor de andere jaren van de zesjarige opleiding. Het enige significante verschil wordt gevonden in het zesde jaar (bij één van beide toetsen) ten voordele van de studenten uit Nijmegen. Bij een vergelijking tussen vijfde- en zesdejaarsstudenten uit Maastricht en studenten uit dezelfde jaren van twee andere Europese universiteiten met een traditioneel curriculum wordt geen significant verschil gevonden in de resultaten voor de klinische vakken. ${ }^{29}$ Het lijkt er dus op dat een probleemgestuurd curriculum geen betere voorbereiding biedt op een examen in de klinische vakken dan een traditioneel curriculum.

\section{Toetsresultaten klinische competentie}

De klinische prestaties zijn op verschillende wijzen gemeten; de onderzoeken worden samengevat in tabel 2. Er zijn veel methodologische tekortkomingen. Over het algemeen zijn er geen significante verschillen tussen de klinische scores van beide sporen, ongeacht of de evaluator een supervisor, een verpleegkundige of de student zelf is. 25323637 De gevonden verschillen liggen vaak in de lijn van de verwachting, bijvoorbeeld afgestudeerden aan een universiteit met een probleemgestuurd curriculum krijgen van supervisoren significant hogere scores voor 'zelfstandig werken en leren' en 'sociale vaardigheden', en afgestudeerden uit een traditioneel curriculum scoren hoger op kennis over basisvakken. ${ }^{38}$ Een enkele keer krijgen studenten of afgestudeerden uit het probleemgestuurde spoor significant hogere klinische scores dan hun collega's uit het traditionele spoor. ${ }^{33}$ Beoordelingen door supervisoren zijn echter subjectief en bijgevolg niet erg betrouwbaar en valide. Beoordelingen van op audio- of videoband opgenomen consulten vallen de ene keer uit in het voordeel van probleemgestuurd en de andere keer in het voordeel van traditioneel onderwijs. ${ }^{20} 39$ Ten slotte zijn studenten uit Maastricht (probleemgestuurde aanpak) significant beter in het stellen 
van de differentiaaldiagnose bij korte schriftelijke casussen dan hun collega's uit Groningen (traditionele aanpak). ${ }^{40}$ Er zijn dus aanwijzingen dat de klinische competentie van afgestudeerden uit een probleemgestuurd curriculum beter is dan die van hun collega's uit een traditioneel curriculum.

\section{Probleemgestuurd leren in een traditioneel curriculum}

\section{Subjectief oordeel van de studenten}

Soms wordt een probleemgestuurde onderwijscomponent in een traditioneel curriculum geïntroduceerd. Het oordeel van de studenten over de nieuwe didactische werkvorm is dan over het algemeen positief. $41-49$

Interessant zijn vergelijkende onderzoeken waarbij dezelfde vragenlijst wordt afgenomen na de probleemgestuurde en de traditionele onderwijscomponent. $\mathrm{Na}$ een stage waarin ambulante geneeskunde onderwezen werd, wordt de probleemgestuurde aanpak gunstiger beoordeeld dan de traditionele. Het enige significante verschil betreft het leren van collega's. ${ }^{50}$ $\mathrm{Na}$ onderwijs over hoofdpijn aan huisartsen wordt het programma als uitstekend beoordeeld door significant meer deelnemers aan de probleemgestuurde versie $(85 \%)$ dan aan de traditionele versie $(35 \%)$. Het oordeel van de huisartsen na de probleemgestuurde component is significant positiever dan dat van hun collega's na de traditionele component over vijf van zeven aspecten, namelijk: 'voldoen aan de doelstellingen', 'voldoen aan de verwachtingen', 'bijdragen aan kennis en vaardigheden', 'nuttig programmamateriaal' en 'de discussies bevorderen het leren'. ${ }^{51}$ De probleemgestuurde onderwijscomponent duurde echter driemaal zo lang als de traditionele.

\section{Prestaties van de studenten}

De bevindingen uit onderzoeken waarin de prestaties van studenten na deelname aan een probleemgestuurde onderwijscomponent worden vergeleken met deze van hun collega's na het volgen van traditionele hoorcolleges staan in tabel 3 . Het gaat dus om studenten aan dezelfde universiteit die hetzelfde traditionele onderwijs kregen met uitzondering van een welbepaalde onderwijscomponent die de helft van de studenten in een probleemgestuurde versie kreeg aangeboden. Dit maakt de vergelijking zuiverder, evenals het feit dat de toetsen voor alle studenten hetzelfde zijn. De vorm en inhoud van de toets varieert wel van onderzoek tot onderzoek. Zelden wordt gebruik gemaakt van de nationale examens van de NBME. 52 Meestal worden specifieke toetsen ontwikkeld, die doorgaans als examen gelden en vaak bestaan uit meerkeuzevragen. Over de psychometrische kwaliteit van de toetsen wordt in de regel niet gerapporteerd. Afgaande op het aantal items zijn de betrouwbaarheid en de validiteit twijfelachtig. Ook het aantal studenten in elke groep is soms erg klein of wordt niet vermeld. ${ }^{41} 53$ Selectie daarentegen speelt de onderzoeken zelden parten. ${ }^{51}$ De studenten konden de didactische werkvorm niet kiezen: ze werden aan een onderwijsvorm toegewezen of het ene studiejaar kreeg traditioneel onderwijs en de daaropvolgende jaargroep probleemgestuurd. Een enkele keer kwam de groepssamenstelling zelfs at random tot stand. ${ }^{54}$ Een follow-upperiode van wat langere duur bemoeilijkt de interpretatie omdat er dan meer factoren een rol spelen dan alleen het genoten onderwijs.

Bij toetsafname kort na de deelname aan de onderwijscomponent wordt over het algemeen geen significant verschil gevonden tussen probleemgestuurd en traditioneel onderwijs. ${ }^{31} 43495052-5557$ 


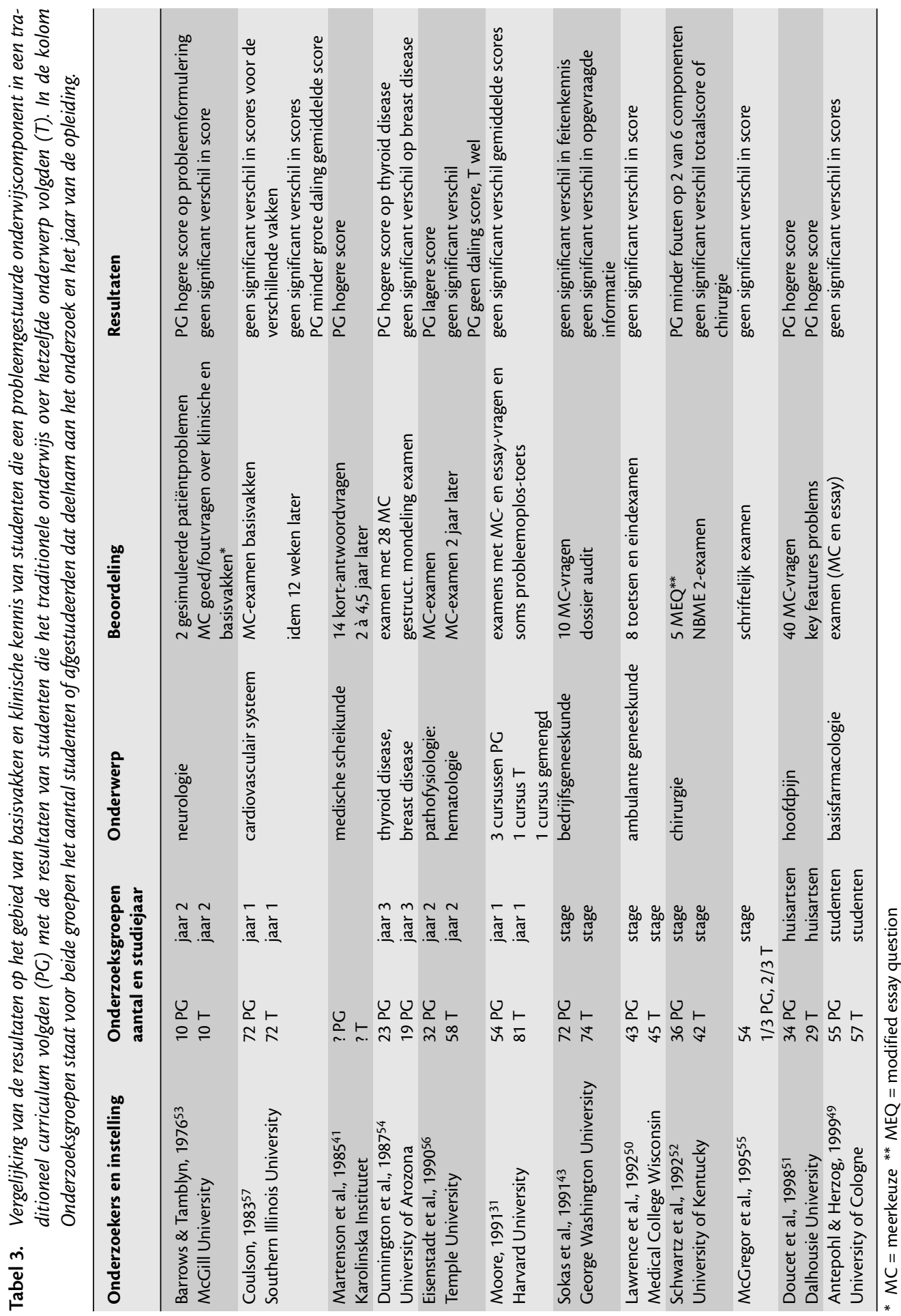


De gevonden verschillen zijn op één uitzondering na in het voordeel van de probleemgestuurde aanpak. ${ }^{51-54} 56 \mathrm{Bij}$ een follow-upmeting 12 weken tot 2 à 4,5 jaar later wordt geen verschil opgemerkt of behaalt de probleemgestuurde groep een significant hogere score. ${ }^{415657}$ Zelfs als er geen verschil is in score, wordt toch gerapporteerd dat de daling van de gemiddelde score significant groter is in de traditionele dan in de probleemgestuurde groep. 5657

\section{Discussie}

Het oordeel van studenten over hun onderwijs is in een probleemgestuurd curriculum over het algemeen gunstiger dan in traditionele curricula. Terugblikkend op hun opleiding voelen de meeste afgestudeerden zich beter of even goed voorbereid in vergelijking met afgestudeerden uit traditionele universiteiten. Studenten uit een probleemgestuurd curriculum maken significant meer gebruik van de bibliotheek en hebben gemiddeld een grondiger leerstijl dan studenten uit een traditioneel curriculum. Eerste- en tweedejaarsstudenten uit een probleemgestuurd curriculum hebben in een aantal studies een significant lagere totaalscore op de basisvakken dan hun collega's uit een traditioneel curriculum. Verschillen op subtoetsen zijn over het algemeen in het voordeel van het traditionele curriculum voor de biomedische basiswetenschappen en van het probleemgestuurde curriculum voor de gedragswetenschappen. Er wordt over het algemeen geen significant verschil gevonden op toetsen in klinische vakken. Tussen studenten uit beide typen curricula bestaan geen significante verschillen in beoordelingen tijdens stages, ofwel de probleemgestuurde studenten scoren hoger. Er zijn aanwijzingen dat de klinische competentie van probleemgestuurde studenten beter is.
Studenten die opgeleid zijn in traditioneel onderwijs, weten na een beperkte ervaring met probleemgestuurd onderwijs deze didactische werkvorm (erg) te appreciëren. Bij toetsen afgenomen kort na deelname aan een probleemgestuurde onderwijscomponent in een traditioneel curriculum zijn de prestaties in vergelijking met die van studenten die alleen traditioneel onderwijs kregen, beter of even goed. De bevindingen tijdens followuptoetsen zijn analoog. Opvallend is dat de daling van de score in de groep die een probleemgestuurde component volgde, kleiner is dan in de traditionele groep. Een probleem hierbij is dat dan niet meer duidelijk is wat nog gemeten wordt. De kennisverwerving in een traditionele onderwijsinstelling kan dus nog verhoogd worden door probleemgestuurde componenten in te lassen.

In vergelijking met een traditioneel curriculum lijkt een probleemgestuurd curriculum studenten dus minder goed voor te bereiden op een examen in de basisvakken, terwijl de voorbereiding op de klinische vakken vergelijkbaar is en de voorbereiding voor klinische competentie wellicht beter. Deze bevindingen lijken onverwacht. Het probleemgestuurd curriculum voldoet immers beter dan het traditionele aan principes uit de cognitieve psychologie die kennisverwerving in de hand werken. Colliver wijt deze discrepantie aan de zwakheid van de theorie en de onnauwkeurigheid van de theoretische concepten. ${ }^{3}$ In reactie op deze aantijging tonen Norman en Schmidt aan de hand van sprekende voorbeelden aan dat in fundamenteel onderzoek in de cognitieve psychologie met nauwkeurige interventies niet-triviale effecten en voor de onderwijspraktijk hoogst relevante resultaten bekomen kunnen worden. ${ }^{58} \mathrm{Zij}$ menen dat interventies op curriculumniveau nooit veel zullen opleveren, onder meer wegens 
de veelheid van factoren die de resultaten beïnvloeden. Zij pleiten dan ook voor meer fundamenteel onderzoek naar aspecten waarvan verondersteld wordt dat deze een gunstige invloed hebben op het leerproces. 58 Wat het probleemgestuurd onderwijs betreft zou bijvoorbeeld onderzoek moeten opgezet worden om aan te tonen welke de werkzame ingrediënten zijn: het probleem als uitgangspunt? het werken in kleine groepen? de zelfstudie? de begeleiding door de tutor? In welke fasen in de medische opleiding en op welke domeinen is de probleemgestuurde aanpak het meest geschikt?

\section{Literatuur}

1. Albanese MA, Mitchell S. Problem-based learning: a review of literature on its outcomes and implementation issues. Acad Med 1993;68:52-81.

2. Vernon DTA, Blake RL. Does problem-based learning work? A meta-analysis of evaluative research. Acad Med 1993;68:550-63.

3. Colliver JA. Effectiveness of problem-based learning curricula: research and theory. Acad Med 2000;75:259-66.

4. Norman GR, Schmidt HG. The psychological basis of problem-based learning: a review of the evidence. Acad Med 1992;67:557-65.

5. Albanese M. Problem-based learning: why curricula are likely to show little effect on knowledge and clinical skills. Med Educ 2000;34:729-38.

6. Schmidt HG, Moust JHC. Studiebeleving van Maastrichtse medische studenten. Medisch Contact 1981;49:1515-8.

7. Holmes DB, Kaufman DM. Tutoring in problembased learning: a teacher development process. Med Educ 1994;28:275-83.

8. Kaufman DM, Mann KV. Basic sciences in problem-based learning and conventional curricula: students' attitudes. Med Educ 1997;31:177-80.

9. Kaufman DM, Mann KV. Students' perception about their courses in problem-based-learning and conventional curricula. Acad Med 1996; 71(Supp 1):S52-4.

10. West M, Mennin SP, Kaufman A, Galey W. Medical students' attitudes toward basic sciences: influence of a primary care curriculum. Med Educ 1982;16:188-91

11. Kaufman A, Mennin S, Waterman R, Duban S, Hansbarger C, Silverblatt H, et al. The New Mexico experiment: educational innovation and institutional change. Acad Med 1989;64:285-94.
12. Moore-West M, Harrington DL, Mennin SP, Kaufman A, Skipper BJ. Distress and attitudes toward the learning environment: effects of a curriculum innovation. Teach Learn Med 1989;3:151-7.

13. Woodward CA, Ferrier B. The content of the medical curriculum at McMaster University: graduates' evaluation of their preparation for postgraduate training. Med Educ 1983;17:54-60.

14. Woodward CA, Ferrier BM. Perspectives of graduates two or five years after graduation from a three-year medical school. J Med Educ 1982;57: 294-302.

15. Rankin JA. Problem-based medical education: effect on library use. Bull Med Libr Assoc 1992;80: 36-43.

16. Blumberg P, Michael JA. Development of selfdirected learning behaviors in a partially teacherdirected problem-based learning curriculum. Teach Learn Med 1992;4:3-8.

17. Lancaster CJ, Bradley E, Smith IK, Chessman A, Stroup-Benham CA, Camp MG. The effect of PBL on students' perceptions of learning environment. Acad Med 1997;72(10 Suppl 1):S10-5.

18. Lieberman SA, Stroup-Benham CA, Peel JL, Camp MG. Medical student perception of the academic environment: a prospective comparison of traditional and problem-based curricula. Acad Med 1997;72(10 Suppl 1):S13-5

19. Kaufman DM, Mann KV. Comparing students' attitudes in problem-based and conventional curricula. Acad Med 1996;71:1096-9.

20. Moore GT, Block SD, Briggs Style C, Mitchell R. The influence of the New Pathway Curriculum on Harvard medical students. Acad Med 1994;69: 983-9.

21. Newble DI, Entwistle NJ. Learning styles and approaches: implications for medical education. Med Educ 1986;20:162-75.

22. Coles CR. Differences between conventional and problem-based curricula in their students' approaches to studying. Med Educ 1985;19:308-9.

23. Newble DI, Clarke RM. The approaches to learning of students in a traditional and in an innovative problem-based medical school. Med Educ 1986;20:267-73.

24. Volder De ML, Grave De WS. Approaches to learning in a problem-based medical programme: a developmental study. Med Educ 1989;23:262-4.

25. Jones JW, Bieber LL, Echt R, Scheifley V, Ways PO. A problem-based curriculum: ten years of experience. In: Schmidt HG, Volder ML de, redactie. Tutotials in problem-based learning: a new direction in teaching the health professions. Assen/Maastricht; Van Gorcum. p. 181-98.

26. Farquhar LJ, Haf J, Kotabe K. Effect of two preclinical curricula om NBME Part I examination performance. J Med Educ 1986;61:369-73. 
27. Goodman LJ, Brueschke EE, Bone RC, Rose WH, Williams EJ, Paul HA. An experiment in medical education: a critical analysis using traditional criteria. JAMA 1991;265:2373-6.

28. Mennin SP, Friedman M, Skipper B, Kalishman S, Snyder J. Performances on the NBME I, II, and III by medical students in the problem-based learning and conventional tracks at the University of New Mexico. Acad Med 1993;68:616-24.

29. Albano MG, Cavallo F, Hoogenboom R, Magni F, Majoor G, Manenti F, et al. An international comparison of knowledge levels of medical students: the Maastricht Progress Test. Med Educ 1996;30:239-45.

30. Verhoeven BH, Verwijnen GM, Scherpbier AJJA, Holdrinet RSG, Oeseburg B, Bulte JA, Vleuten $\mathrm{CPM}$ van der. An analysis of progress test results of PBL and non-PBL students. Med Teach 1998;20:310-6.

31. Moore GT. The effect of compulsory participation of medical students in problem-based learning. Med Educ 1991;25:140-3.

32. Phelan ST, Jackson JR, Berner EA. Comparison of problem-based and traditional education on student performance in the obstetrics and gynecology clerkship. Obstetrics Gynecol 1993;82:159-61.

33. Richards BF, Ober KP, Cariaga-Lo L, et al. Ratings of students' performances in a third-year internal medicine clerkship: a comparison between problem-based and lecture-based cirrucula. Acad Med 1996;71:187-9.

34. Shin JH, Haynes RB, Johnston ME. Effect of problem-based, self-directed undergraduate education on life-long learning. Can Med Assoc J 1993;148:969-76.

35. Claessen HF, Boshuizen HP. Recall of medical information by students and doctors. Med Educ 1985;19:61-7.

36. Santos-Gomez L, Kalishman S, Rezler A, Skipper B, Mennin SP. Residency performance of graduates from a problem-based and a conventional curriculum. Med Educ 1990;24:366-75.

37. Barnsley L, Cameron R, Engel CE et al. Ratings of performance of graduates from traditional and nontraditional medical schools. Teach Learn Med 1994;6:179-84.

38. Rolfe IE, Andren JM, Pearson S, Hensley MJ, Gordon JJ. Clinical competence of interns. Med Educ 1995;29:225-30.

39. Grol R, Mokkink H, Helsper-Lucas A, Tielens V, Bulte J. Effects of the vocational training of general practice consultation skills and medical performance. Med Educ 1989;23:512-21.

40. Schmidt HG, Machiels-Bongaerts M, Hermans H, Cate ThJ ten, Venekamp R, Boshuizen HPA. The development of diagnostic competence: comparison of a problem-based, an integrated, and a conventional medical curriculum. Acad Med 1996;71;658-64.

41. Martenson D, Eriksson H, Ingelman-Sundberg M. Medical chemistry: evaluation of active and problem-oriented teaching methods. Med Educ 1985; 19:34-42.

42. West DA, West MM. Problem-based learning of psychopathology in a traditional curriculum using multiple conceptual models. Med Educ 1987;21:151-6.

43. Sokas RK, Diserens D, Johnston MA. Integrating occupational health into the medicine clerkship using problem-based learning. J Gen Intern Med 1991;6:450-4.

44. Vernon DTA, Campbell JD, Dally JC. Problembased learning in two behavioral sciences courses at the University of Missouri - Columbia. Acad Med 1992;67:349-50.

45. Vasconez HC, Donnelly MB, Mayo P, Schartz RW. Student perceptions of the effectiveness of a problem-based surgery curriculum. Acad Med 1993;68(Suppl):S28-S30.

46. Morrison JM, Murray TS. An experiment in problem-based learning. Med Educ 1994;28:139-45.

47. Bernstein P, Tipping J, Bercovitz K, Skinner HA. Shifting students and faculty to a PBL curriculum: attitudes changed and lessons learned. Acad Med 1995;70:245-7.

48. Schwartz RW, Donnelly MB, Sloan DA, Strodel WE. Residents' evaluation of a problem-based learning curriculum in a general surgery residency program. Am J Surg 1997;173:338-41.

49. Antepohl W, Herzig S. Problem-based learning versus lecture-based learning in a course of basic pharmacology: a controlled, randomized study. Med Educ 1999;33:106-13.

50. Lawrence SL, Grosenick DJ, Simpson DE, Susteren TJ van. A comparison of problem-based and didactic approaches to learning on an ambulatory medicine clerkship. Teach Learn Med 1992;4:221-4.

51. Doucet MD, Purdy RA, Kaufman DM, Langille DB. Comparison of problem-based learning and lecture format in continuing medical education on headache diagnosis and management. Med Educ 1998;32:590-6.

52. Schwartz RW, Donnelly MB, Nash PP, Johnson SB, Young B, Griffen WO. Problem-based learning: an effective educational method for a surgery clerkship. J Surg Res 1992;53:326-30.

53. Barrows HS, Tamblyn RM. An evaluation of problem-based learning in small groups utilizing a simulated patient. J Med Educ 1976;51:52-4.

54. Dunnington G, Witzke D, Rubeck R, Beck A, Mohr J, Putnam C. A comparison of the teaching effectiveness of the didactic lecture and the problem-oriented small group session: a prospective study. Surgery 1987;102:291-5. 
55. McGregor DB, Arcomano TR, Bjerke HS, Little AG. Problem orientation is a new approach to surgical education. Am J Surg 1995;170:656-9.

56. Eisenstaedt RS, Barry WE, Glanz K. Problembased learning: cognitive retention and cohort traits of randomly selected participants and decliners. Acad Med 1990;65(Suppl):S11-S12.

57. Coulson RL. Problem-based student-centered learning of the cardiovascular system using the problem-based learning module (P.B.M.). Physiologist 1983;26:220-4.

58. Norman GR, Schmidt HG. Effectiveness of problem-based learning curricula: theory, practice and paper darts. Med Educ 2000;34:721-8.
De auteurs:

J. Beullens is psycholoog en wetenschappelijk medewerker aan de Onderwijskundige Dienst van de Faculteit Geneeskunde van de Katholieke Universiteit Leuven. Prof. dr. H. Jaspaert, pedagoog, is hoofddocent en leidt de Onderwijskundige Dienst van de Faculteit Geneeskunde van de Katholieke Universiteit Leuven.

Correspondentieadres:

Johan Beullens, Onderwijskundige Dienst Faculteit Geneeskunde, KU Leuven, Minderbroedersstraat 17, B-3000 Leuven, België; E-mailadres: Johan.Beullens@ med.kuleuven.ac.be.

\section{Summary}

Introduction: This article presents a review of the literature comparing the effects of problem-based learning with those of traditional approaches. A distinction is made between a problem-based curriculum and a problem-based course in an otherwise traditional curriculum.

Method: A Medline search was performed to retrieve articles published in the period 1966-1998 on problem-based learning in undergraduate and postgraduate medical curricula.

Results: Students in a problem-based curriculum generally express greater satisfaction with teaching compared with their colleagues in a traditional curriculum. Students in a problem-based curriculum make more use of the library and other resources. They make more use of a deep learning approach, whereas that of their colleagues in a traditional curriculum tends to be more superficial. The differences in results for basic sciences between problem-based and traditional curricula are in favour of the traditional approach and the differences concerning clinical competence are in favour of the problem-based approach. In traditional medical schools students taking part in a problem-based course find this a positive experience. Moreover, their test results are as good as or better than those of their colleagues who took the traditional course on the subject.

Discussion: The studies can be critiqued on various methodological aspects. Nevertheless it is clear that students are appreciative of problem-based learning. Traditional teaching generally results in higher scores for basic sciences and problem-based curricula in higher scores for behavioural sciences and clinical competence. There are indications that the learning of students in traditional curricula benefits from the introduction of problem-based courses. Further studies are needed to explore the aspects of problem-based learning that are beneficial to the learning of students. (Beullens J, Jaspaert H. Problem based learning: a review of the literature. Dutch Journal of Medical Education 2001;20(3): 100-113.) 